\title{
UMA ANÁLISE ACERCA DAS RELAÇÕES INTERACIONAIS NO ESPAÇO DISCURSIVO SALA DE AULA À LUZ DO FILME ENTRE OS MUROS DA ESCOLA
}

\author{
Layane Dias Cavalcante Viana* \\ Nicéia Maria de Figueiredo Souza Melo \\ Mônica Matos Anunciação ${ }^{* * *}$
}

RESUMO: As interações que ocorrem em sala de aula são permeadas por relações de poder e podem ser ainda repletas de conflitos. A linguagem é o grande campo de batalha onde são travadas e materializadas essas relações conflituosas e de poder. Objetiva-se neste artigo analisar como se configura o discurso pedagógico interacional numa sala de aula do ensino básico a partir de cenas do filme "Entre os muros da Escola", dirigido por Laurent Cantet, abordando a teoria de mecanismos de controle do discurso de Foucault (2008) e do discurso pedagógico, enquanto um discurso autoritário, segundo Orlandi (1987). Pretende-se verificar em que medida o discurso autoritário e a interação, ou a falta dela podem interferir na construção de sentidos por parte dos alunos.

PALAVRAS-CHAVE: Construção do sentido; Discurso; Interação; Relações de poder; Sala de aula.

* Mestre em Letras: Cultura, Educação e Linguagens pela Universidade Estadual do Sudoeste da Bahia (Uesb). Especialista em Linguística também pela Uesb. Professora da Faculdade Independente do Nordeste (Fainor). Membro e pesquisadora do Grupo de Pesquisa em Linguagem e Educação - GPLED/CNPq/ Uesb.

** Mestre em Letras: Cultura, Educação e Linguagens pela Universidade Estadual do Sudoeste da Bahia (Uesb).

*** Doutoranda em Letras com área de concentração em Literatura e Representações culturais na Universidade Federal da Bahia (Ufba). Mestre em Letras - área de concentração em Cultura, Educação e Linguagens pela Universidade Estadual do Sudoeste da Bahia (Uesb). 


\section{Introdução}

O filme "Entre os muros da Escola" é um longa metragem que apresenta a atuação de um professor de língua e literatura francesa em uma escola de ensino básico da periferia de Paris. François Marin, vivido pelo ator François Bégaudeua, leciona em uma turma de sétima série ${ }^{1}$, alunos adolescentes imigrantes ou filhos de imigrantes, cada um com seus conflitos étnicos, religiosos, de classe e ideológicos. Toda a trama é encenada em ambiente escolar: nas salas, corredores, nos pátios. Sustenta-se por meio de longos diálogos que buscam retratar as tensões vivenciadas entre professor e aluno, aluno e aluno nesse rico espaço discursivo: sala de aula.

Para Souza (2009), a sala de aula, enquanto uma instância discursiva, não é restrita à exposição de conteúdos. As falas que circulam nesse espaço

[...] são falas marcadas, na acepção de discursos, isto é, produções ideológicas situadas em tempo e espaço definidos [...] em que os agentes sociais (professor e aluno) expõem valores e objetam escolhas, impregnando as suas falas com a negociação do sentido (SOUZA, 2009. p. 99)

Há pouco mais de dez anos de seu lançamento, a realidade interacional demonstrada no filme acerca das relações conflituosas que se instauram em uma típica sala de aula de adolescentes ainda é muito próxima às salas de aula atuais. Sua análise é prenhe de significado, sugere reflexão e tem muito a ensinar sobre as relações dialógicas e de poder presentes nesse ambiente de aprendizado.

Na relação interacional entre professor e aluno, no filme, é notória a dificuldade do mestre em se relacionar com seus alunos e de criar vínculos afetivos com eles. A forma como o professor conduz as interações e tenta impor sua cultura parece não fazer sentido para os alunos, pois há clara dificuldade de comunicação entre eles, relacionada principalmente à linguagem empregada pelo professor a qual soa muito distante da linguagem utilizada pelos alunos. Uma outra questão é o fato de, além de a linguagem parecer ser um

${ }^{1} \mathrm{Na}$ atual configuração do sistema educacional brasileiro, a $7^{\mathrm{a}}$ série corresponde ao $8^{\circ}$ ano do ensino fundamental. 
obstáculo, haver choque entre culturas e o grave problema de a escola estar distante daquilo que os alunos esperam dela. A trama evidencia a decadência de um modelo tradicional de ensino autoritário que desconsidera a diversidade e as expectativas dos educandos. Para o professor protagonista, a articulação e a troca de saberes são negligenciadas e a relação autoritária, em sua prática, uma constante.

De modo geral, o filme apresenta questões universais ligadas à educação. (In)disciplina, autoridade, desinteresse pelas aulas, repetência, desrespeito, bagunça e conflitos de relacionamento, como também conflitos identitários e aceitação de si permeiam a história dos protagonistas desse filme premiado vencedor da Palma de Ouro no Festival de Cannes em 2008.

Discutiremos a partir de cenas do referido filme como se configura o discurso pedagógico interacional numa sala de aula do ensino básico, destacando a teoria de mecanismos de controle do discurso de Foucault (2008) e do discurso pedagógico, segundo Orlandi (1987). Será verificado, por meio de transcrições de cenas interacionais, como o discurso pedagógico, que se assume enquanto um discurso autoritário, e a interação, ou a ausência dela trazem implicações para a construção de sentidos feita pelos alunos.

\section{Relações de poder: o discurso controlado em sala de aula}

Toda interação pressupõe uma relação de poder. Na configuração discursiva da sala de aula, onde geralmente ocorrem as interações entre alunos e professor e entre alunos e alunos, estão instauradas, nessas interações, certas hierarquias que se configuram como relações de poder.

A sala de aula, enquanto um fenômeno social e ideologicamente marcado, pode ser vista com uma

[...] arena de conflitos de vozes e de valores mutáveis e concorrentes. Essa perspectiva da sala de aula como heteroglossia, constituindo numa estratificação, dinâmica e hierarquicamente organizada, de vozes e de valores, concorrendo uns com os outros para a posição hegemônica do dominante, traz consigo a necessidade da negociação na sala de aula. (SOUZA, 1995. p. 24) 
Negociação essa que deve ocorrer via linguagem. É pela linguagem que as regras de interação próprias do contexto de aula são explicitadas e o controle da interação é exercido pelo professor, já que, em sala de aula, ele é a voz de autoridade.

Mediante essas relações de interação que também se revelam como relações de poder, já que envolvem o discurso, os sujeitos e a linguagem. Analisaremos os procedimentos de controle do discurso que permeiam cenas típicas de interação numa sala de aula, verificando alguns dos mecanismos de controle que atingem o discurso pedagógico interacional à luz da teoria foucaultiana.

Em $A$ ordem do discurso Foucault (2008) desenvolve a ideia de que as civilizações tendem a uma veneração do discurso, e que por ele, também possuem uma espécie de temor. Como consequência disso, sistemas de controle do discurso foram criados, de forma a dominar a proliferação desses discursos.

Segundo Foucault,

[...] em toda sociedade a produção do discurso é ao mesmo tempo controlada, selecionada e redistribuída por certo número de procedimentos que têm por função conjurar seus poderes e perigos, dominar seu acontecimento aleatório, esquivar sua pesada e temível materialidade. (FOUCAULT, 2008, p. 8-9)

Dessa forma, serão problematizados os mecanismos controladores do discurso de Foucault (2008), colocando em evidência noções como as de interdição e vontade de verdade para a análise das cenas em questão, conceitos que correspondem, grosso modo, à palavra proibida e à oposição entre o verdadeiro e o falso, os quais serão melhor problematizados a partir da análise das cenas em questão.

Em uma das cenas do filme, há o diálogo entre o professor e seus alunos, no momento em que ele discute a conjugação de alguns verbos. Ver cena transcrita.

Professor François: - Alguém pode me dar um exemplo do imperfeito do subjuntivo? ... Não acredito, Khoumba! Mas estou ouvindo.

Aluna Khoumba: - Espere... acho que vou errar, heim?

Professor François: - Também acho.

Aluna Khoumba: - Eu fusse... 
Professor François: - Fusse, é claro, do verbo fusser. Eu fusse, tu fusses...

Aluna Khoumba: - Não é eu fusse? Nós fussemos, vós fusseis... Professor François: - Ótimo, não é tanta besteira. Você lembra da terminação do imperfeito do subjuntivo. - Imaginem que eu diga... É preciso que eu seja... digamos saudável. O que é este seja aqui? Eva?

Aluna Eva: - É o presente do subjuntivo.

Professor François: - Muito bem. É o presente do subjuntivo. Para ter o imperfeito do subjuntivo vou precisar concordar o tempo. Coloco um passado aqui: Era preciso...

Aluna Khoumba: - Era preciso que eu tinha sido!

Professor François: - Era preciso que eu..., Khoumba!

Aluna Khoumba: - Fusse...

Professor François: - Fosse.

Aluna Esmeralda: - Acha que vou falar pra minha mãe: precisava que eu fosse sido?

Professor François: - Não é precisava que eu fosse sido. Leia a frase antes de reclamar.

Aluna Esmeralda: - Era preciso que eu fosse saudável.

Professor François: - É uma concordância verbal.

Aluna Khoumba: - Ninguém fala assim. É sério! Eu tinha razão, era fusse.

Professor François: - Será que posso responder à pergunta que me fizeram?

Se estiverem interessados mesmo...

Aluna Khoumba: - Eu autorizo.

Professor François: - Percebo que antes mesmo de aprender o uso do imperfeito do subjuntivo, já estão me dizendo que ele não serve para nada! Primeiro, aprendam. Depois, vocês podem questionar o uso dele.

Algumas alunas: - Por que está criticando a gente?

Aluna não identificada: - Eles têm razão. A linguagem que a gente usa é diferente. Essa é antiga. Nem minha avó fala assim.

Aluno Boubacar: - Nem seu bisavô falava. Isso é coisa da Idade média!

Professor François: — Não é da idade média!

Aluna Khoumba: - É coisa de burguês.

Aluna não identificada: - Quando foi a última vez que ouviu alguém falando assim?

Professor François: - Ontem, conversando com meus amigos. É que o problema...

Aluno Boubacar: - Uma pessoa normal. Gente normal não fala assim! Nas ruas, ninguém fala assim!

Professor François: - Ei, ei, ei, posso responder? Eu gosto de discutir, mas com calma. É claro que é verdade que nem todos falam 
assim. É raro alguém que fale. Eu diria que só os esnobes usam o imperfeito do subjuntivo.

Os alunos estranham bastante a conjugação para certos verbos pois, segundo eles, não é essa a maneira que se fala e que se ouve falar no dia a dia. Os alunos questionam a linguagem, a variante de linguagem ensinada pelo professor, pois de acordo com eles é uma linguagem muito distante da utilizada na vida diária. Um deles chega a concluir que não é a língua de gente normal. Dessa forma, os estudantes questionam o professor em sua autoridade, em sua "verdade" por meio de palavras proferidas por ele de que a forma ensinada é a que se deva falar, ou seja, de se conjugar certos verbos. $\mathrm{Na}$ cena, fica claro que o professor tenta impor, através de uma vontade de verdade, fazendo uso da linguagem, a sua "verdade" que está mascarada pelas regras da gramática normativa que toda língua possui.

De acordo com Foucault (2008), a verdade é historicamente construída, o que temos em um enunciado, não é uma verdade, mas uma vontade de verdade. As verdades são sustentadas por um sistema de instituições que as impõem e reconduzem. A vontade de verdade funciona por deslocamentos de verdade "[...] tende a exercer sobre os outros discursos [...] uma espécie de pressão e como que um poder de coerção" (FOUCAULT, 2008, p. 18). Mediante a fala do professor, quando ele ensina a forma "correta" de conjugação de alguns verbos, essa mesma fala está repleta do discurso de autoridade da Gramática Normativa (GN).

É bastante interessante vermos como essa gramática se constituiu como uma "verdade", ou melhor, como uma vontade de verdade, um discurso de autoridade no decorrer dos séculos. As regras gramaticais impostas pela GN tendem a exercer sobre os outros discursos, a exemplo de tantos outros "falares" legitimados que existem na língua, uma pressão que se transforma em coerção. É essa coerção que, provavelmente, sentem os alunos do filme em relação à língua do dia a dia, língua esta, legítima, viva e bastante eficaz nas comunicações rotineiras. "A vontade de verdade é um sistema de exclusão 'institucionalmente constrangedor'. Possui mecanismos de imposição daquilo que se considera o 
‘verdadeiro' e fora dele estarão todos os discursos dissonantes” (COSTA; FONSECASILVA, 2014, p. 51).

A variação linguística padrão regida pela GN é, na verdade, uma língua “artificialmente" criada para disciplinar, controlar, refrear, limitar a língua e, consequentemente, os seus usuários. Geraldi (2011) em O texto na sala de aula pontua questões acerca da atividade linguística artificial instituída na prática escolar. Segundo ele, há um falseamento na interlocução estabelecida em sala de aula. Os papeis assumidos nessa interlocução estão drasticamente marcados: o professor e a escola, aqueles que ensinam e o aluno que aprende (sempre que puder). "Tentar ultrapassar essa artificialidade é efetivamente tentar assumirse como um 'tu' da fala do aluno, na dinâmica de trocas do eu/tu." (GERALDI, 2011, p. 89). O mesmo autor ainda acrescenta que essa artificialidade do uso da linguagem compromete significativamente a aprendizagem na escola de uma língua ou da variante dessa mesma língua. Essa dificuldade de aprendizagem e até mesmo de resistência em relação à língua padrão também são notórias no filme. A aluna Khoumba, no diálogo transcrito acima, afirma que "ninguém fala assim" referindo-se ao modo de falar correspondente à norma padrão. Não só ela, mas todos os alunos da classe possuem grande resistência no ensino da língua seguindo regras da Gramática Normativa. Resistência que, possivelmente, é gerada por uma forte imposição dessa mesma "língua" que encontra respaldo num dos procedimentos de controle do discurso de Foucault (2008).

Em outra cena é possível presenciarmos mais um procedimento de controle do discurso, a interdição. Em uma breve descrição dessa cena, tem-se uma pequena discussão entre o professor e um de seus alunos - Souleymane. Nessa discussão, duas alunas - Louise e Esmeralda - interferem. Nessa conversa acalorada em sala de aula, as alunas "impertinentes" irritam o professor a ponto de ele se exceder em sua fala e dizer que essas alunas, em um evento específico (conselho de classe) se comportavam como vagabundas. Ver cena transcrita abaixo.

Professor François: - Desculpe, mas rindo daquele jeito, vocês pareciam duas vagabundas.

Aluna Louise: - Não pode tratar suas alunas assim. 
Professor François: - Não é tratar, é xingar. Não disse que são vagabundas. Disse que no conselho de classe, naquele momento, vocês se comportaram como vagabundas.

O fato de o professor chamar as alunas de vagabundas ocasionou um grande desconforto em sala de aula. $\mathrm{Na}$ ordem discursiva desse espaço há uma série de interdições. O xingamento, por parte do professor, materializado na palavra "vagabunda" é uma dessas interdições, pois se configura como uma ofensa, um insulto, um desrespeito. Em uma sala de aula, os discursos a serem circulados são devidamente selecionados pela instituição escola, pelo professor, que é o mediador mais imediato das interações que ali ocorrem, pelos livros didáticos, enfim, não se tem o direito de dizer tudo o que se deseja, principalmente, o professor, que é o mediador-mor das relações em sala de aula. É o que poderíamos chamar de ritual da circunstância que, no caso em questão, é a sala em um evento de aula. É quando o contexto é desfavorável a determinados posicionamentos, comentários. Sobre isso, Foucault vai nos dizer que:

Sabe-se bem que não se tem o direito de dizer tudo, que não se pode falar de tudo em qualquer circunstância, que qualquer um enfim, não pode falar de qualquer coisa. Tabu do objeto, ritual da circunstância, direito privilegiado ou exclusivo do sujeito que fala [...]. (FOUCAULT, 2008, p. 9)

Nas palavras de Foucault, todos esses dois procedimentos de controle e de delimitação do discurso (vontade de verdade e interdição) até aqui explanados "se exercem de certo modo do exterior; funcionam como sistemas de exclusão; concernentes, sem dúvida, à parte do discurso que põe em jogo o poder e o desejo.” (2008, p. 19). As interdições que atingem o discurso revelam a ligação do discurso com o desejo e o poder. "O discurso não é simplesmente aquilo que traduz as lutas ou os sistemas de dominação, mas aquilo por que, pelo que se luta, o poder do qual nos queremos apoderar"'(FOUCAULT, 2008, p. 10).

Todas essas interações até aqui analisadas desencadeiam conflitos em sala de aula e são atravessadas por relações de poder. Na ordem discursiva da sala de aula, o professor detém o discurso de autoridade, e os alunos para entrarem nessa ordem discursiva têm que se "submeter" à autoridade imposta pelo professor, quando isso não ocorre, presenciamos 
os conflitos, e mecanismos de controle entram em jogo de modo a cercear o discurso pedagógico. A interdição pode ser identificada sob três formatos, conforme o próprio Foucault (2008), compreendida e percebida em diversos contextos em que os discursos circulam e uma leitura possível a respeito de outro formato em que aparece é a de que ela possua um funcionamento tácito em que algumas posições de sujeito estão autorizadas a falar, enquanto outras ficam sem vOz, sem legitimidade para assumir o protagonismo interacional. Trataremos dessa outra vertente da interdição, sob outra perspectiva teórica na seção seguinte.

\section{Discurso pedagógico: um discurso de poder}

A presença/ausência de interação entre professor - aluno, aluno - aluno, família escola reflete o comportamento dos alunos em sala de aula. Nesse contexto, a sala de aula é regulada por diversos discursos, sendo discurso autoritário o predominante.

Para Orlandi (1987) o discurso pode ser caracterizado, em seu funcionamento, por três tipos distintos: discurso lúdico, discurso polêmico e discurso autoritário.

O discurso pedagógico, segundo a autora, tem se apresentado como um discurso autoritário. Ela, em seu texto: $O$ discurso pedagógico: a circularidade, procura caracterizar o discurso pedagógico como um discurso autoritário, em que nele o referente está "ausente", há a presença de um único agente que abafa os outros interlocutores visto que, esse tipo de discurso não dá oportunidade para o dizer do aluno. É um discurso em que não há reversibilidade, mas sim um controle, ocasionando um distanciamento entre professores e alunos. Os papéis sociais que cada um exerce são nitidamente delineados. Cada um em seu lugar, como se os alunos fossem assujeitados, seres passivos diante do professor. Essa reflexão empreendida por Orlandi (1987) acerca do discurso autoritário que tem predominado nas salas de aula de modo geral, pode ser, também, ilustrada por meio das interações do Filme em foco para a análise.

Em um dado momento, o professor, François, profere a seguinte frase: "Cale a boca e leia". O enunciado revela claramente a intenção autoritária de um professor que 
deseja silenciar a voz dos seus alunos, vislumbrá-los enquanto instrumentos de comando, seres passivos, sem vozes, ausentes no processo interativo.

No discurso autoritário o referente está "ausente", oculto pelo dizer; não há realmente interlocutores, mas um agente exclusivo, o que resulta na polissemia contida. (o exagero é a ordem no sentido em que se diz 'isso é uma ordem', em que o sujeito passa a instrumento de comando) Esse discurso recusa outra forma de ser que não a linguagem. (ORLANDI, 1987, p. 15-16)

Essa polissemia contida ignora a pluralidade, a variedade de culturas e as diferenças sociais, abafa e reprime a fala dos alunos, domina e controla o discurso pedagógico. O que ainda pode ser perceptível no filme quando o professor utiliza palavras que, para os alunos, são rebuscadas e de difícil sentido e entendimento, pois utilizam uma linguagem mais popular, permeada de gírias, diferente do "discurso" rebuscado do professor. A linguagem, dessa forma, é reduzida à importância de seu caráter interativo pelo dizer de um único interlocutor que transforma o discurso pedagógico num discurso de poder, autoritário.

Esse discurso autoritário é gerador de conflitos, pois constantemente são noticiados fatos ocorridos na escola de desrespeito e violência entre professor e aluno, bem como entre alunos e alunos. Estudantes queixam-se de perseguições de professores, de desconfianças de sua capacidade para realizar alguma atividade solicitada e em aprender o conteúdo. O clima de tensão se estende também aos professores que se sentem desrespeitados fazendo com que o discurso autoritário seja ainda mais reforçado entre eles como sugere várias cenas do filme. Como exemplo, algumas outras falas do professor no filme ilustram esse comportamento: "trata de tirar o capuz, por favor", "Quero deixar uma coisa clara no início do ano" em que o professor faz uso da linguagem como claro exercício de poder, em que provém dele a voz segura e autossuficiente na tentativa de um ambiente de interação unilateral, materializado pelo uso em sua linguagem dos verbos no modo imperativo, uso claro de verbos como "querer" e "poder" que embora algumas frases venham finalizadas ou antecedidas de expressões educadas e gentis como "por favor", querem tão somente camuflar um discurso que quer se manter enquanto, de fato, autoritário. 
[...] parece-nos que, enquanto discurso autoritário, o DP [ Discurso Pedagógico] aparece como discurso do poder, isto é, como em R. Barthes, o discurso que cria a noção de erro e, portanto, o sentimento de culpa, falando nesse discurso, uma voz segura e auto-suficiente. A estratégia, a posição final, aparece como o esmagamento do outro [...] A estratégia básica das questões adquire a forma imperativa, isto é, as questões são questões obrigativas (parentes das perguntas retóricas). (ORLANDI, 1987, p. 17, grifos do autor.)

\section{A dinâmica das interações e suas interfaces com a produção dos sentidos}

A aula é um evento linguístico marcado paralelamente pela ampliação da "convivência2" entre culturas e consequente exacerbação de conflitos. Nesse evento, os participantes têm seus discursos atravessados por fluxos culturais diversos de modo que a aprendizagem resulta de procedimentos sociointeracionais entre os participantes, empenhados na construção do sentido e do conhecimento. Propomos, neste momento, elucidar a dinâmica das interações nas aulas do professor François, com destaque para as interações dialógicas entre professor e aluno e entre alunos em que observaremos as ocorrências de interação e construção de sentidos pelos discentes.

A dinâmica das interações nas aulas influencia decididamente na construção dos sentidos pelos alunos. Existe certa dificuldade por parte de muitos professores em fazer com que os alunos atribuam sentidos ao que lhes é ensinado em sala de aula. Pesquisas no campo da psicologia da aprendizagem compreendem a aprendizagem como o resultado de processos interacionais entre o aprendiz e interlocutores mais competentes, configurando o que Vygotsky (1978) denomina de Zona de Desenvolvimento Proximal (ZPD):

a distância entre o nível de desenvolvimento real conforme determinado pela capacidade independente de resolução de problemas e o nível de desenvolvimento em potencial conforme determinado pela habilidade de resolver problemas sob a orientação de adultos ou em

${ }^{2}$ Nota-se no filme que não há uma convivência pacífica entre culturas. 
colaboração com pares mais competentes. (VYGOSTSKY, 1978, p. 86 apud MOITA LOPES, 1994, p. 108)

É possível depreender a partir da noção de ZDP que a cognição é de caráter social e ocorre mediante procedimentos sociointeracionais possibilitando negociar a construção dos sentidos por parte de aprendizes e interlocutores. Que sirva de exemplo a cena transcrita abaixo da película fílmica sob análise:

Professor François: — Sim, Damien?

Aluno Damien: - Argentaria.

Professor François: — "Argentaria." O que quer dizer argentaria? Aluno Damien: - São os habitantes da Argentina.

Professor François: - É isso aí. Os habitantes da Argentina.

(Alunos riem)

Professor François: - É claro que não. Damien, como se chama os habitantes da Argentina?

Aluno Damien: - Argentários.

Professor François: - Você sabe. Não vê futebol na TV?

(Outra aluna levanta a mão, mas o professor continua.)

Professor François: - A seleção da Argentina. Eles são jogadores...

Aluno Damien: - De futebol!

(Risos da turma)

Professor François: - Outras palavras difíceis do texto? Bom, continuando...

É possível inferir, a partir de cenas como essas, que grande parte da dificuldade dos alunos em atribuir sentido ao que lhes é ensinado tem as seguintes causas: a) pouco espaço em sala de aula para a manifestação das ideias dos alunos devido ao padrão de aula escolhido pelo professor - aula expositiva, exposição apenas pelo professor; b) as concepções dos alunos são, geralmente, desconhecidas pelo professor; e c) as possibilidades de ligação entre o que é exposto e as ideias preliminares dos alunos são reduzidas.

A interação é fator determinante na construção dos sentidos, pois a falta dela se impõe como um problema de mão dupla, uma vez que a aprendizagem depende fortemente da capacidade dos alunos atribuírem sentidos aos conhecimentos por meio da mediação do professor. A percepção por parte do professor dos sentidos que circulam em sala de aula, 
por sua vez, depende das oportunidades oferecidas para que os alunos se manifestem e da atenção do professor a essas manifestações. Para Mortimer e Machado (1997) apud (SOCHA e MARIN, 2009, p. 4), deve haver permissão por parte do professor das contrapalavras abrindo espaço para a interação verbal. Como consequências dessa abertura, a fala do aluno passa a ser vista como elemento de qualidade e há maior facilidade na tomada de decisões, pois as palavras que carregamos aumentam as possibilidades de compreensão do texto e também do mundo, uma vez que as palavras, mesmo sendo nossas, são também de outros e estão preparadas para receber, hospedar e modificar-se frente às novas palavras que o discurso nos apresenta. Elas, por sua vez, se tornam em novas contrapalavras num processo ininterrupto de constituição da singularidade de cada indivíduo. As contrapalavras, nesse sentido, são um lugar de construção, de produção de sentido.

Os atores envolvidos no discurso agem nas estruturas de participação que atendem às normas próprias de direitos e deveres interacionais. Em outro momento do longa-metragem, em mais uma de suas aulas, o professor François apresenta um texto aos alunos solicitando-os que apontem as palavras desconhecidas e pede à aluna Henriette que se manifeste:

Professor François: - Henriette, dê um exemplo. Tem alguma palavra no texto que não entendeu? Imagino que sim.

(A colega ao lado percebe o constrangimento de Henriette e sopra uma palavra para a colega de carteira.)

Aluna Henriette: - Doravante.

Professor François: — “Doravante". Obrigado, Samantha, por ter soprado. Acho que está bom.

A participação de Henriette não atende às expectativas do professor. No espaço sala de aula, os participantes, professor e alunos, têm seus papéis estabelecidos por esse evento social, mas nem todos os alunos participam efetivamente desse evento e atuam em suas estruturas de participação devido a motivos diversos como diferenças culturais ou falta de interesse ao que está sendo proposto pela escola, exemplo de Henriette.

A disposição funcional da participação do professor e dos alunos na sala de aula, sob analise, é dominada pelo professor que controla a distribuição dos turnos de fala após 
o aluno ter levantado a mão, embora não contemple a solicitação de alguns deles: "Sim, Esmeralda?”, "Burak?”; "Henriette, dê um exemplo”. Mas isso não significa que os alunos do professor François atendam ao padrão de interação próprio de uma sala de aula típica em que os alunos são controlados pelo professor, conforme descreve Cazden (1988) apud (MOITA LOPES, 1994, p. 111). Embora solicitem o turno de fala, os alunos mostram-se, em muitos momentos, dispersos, além de ficar evidente a falta de respeito mútuo entre professor - aluno e aluno - aluno. Para que possamos experimentar, ainda que sugestivamente, como se processa mais um evento interativo numa sala de aula, transcrevemos um outro episódio exemplar do filme.

Professor François: -Bom, agora temos suculento. (...) De onde vem suculento?

Aluno não identificado: - Suco.

Aluno Boubacar: -De cu lento.

Professor François: -Muito engraçado, Boubacar. (...) Vou fazer uma frase com suculento. "Bill se delicia com um suculento... cheeseburger."

Aluno Chérif: - Cheeseburger é uma porcaria.

Professor François: - Quem disse isso? Eu gosto de cheeseburger.

Aluno Chérif: - Por que escolheu cheeseburger?

Aluna Khoumba: - Pronto, justamente!

Professor François: - Já que diz que porcaria, você acha que cheeseburger não é suculento?

Aluno Chérif: - Beleza, mas cheeseburger não é bom.

Professor François: - Certo. Só comentei isso para deixar vocês com uma pulga atrás da orelha.

Aluna não identificada: - O que é isso?

Professor François: - O que é o quê?

A mesma aluna: - Esse lance da pulga?

(Os alunos riem.)

Professor François: - Ficar com a pulga atrás da orelha. Não conhece essa expressão? [...]

Aluna Khoumba: - E por que sempre bota esse Bill?

Professor François: -Assobio?

Aluna Khoumba: - Assobio, não. Esse Bill aí.

Aluna Esmerada: - Bill!

Aluna Khoumba: - Sempre bota nomes esquisitos...

Professor François: -Não é esquisito. É o nome de um presidente recente dos EUA, lembra? 
Aluna Khoumba: - Por que não bota Aïssata, ou Rachid, ou Hamed...

Aluna Esmerada: - sempre coloca nomes coxinhas.

Professor François: -Nomes o quê?

Aluna Esmerada: - Coxinhas.

Professor François: -Coxinhas como?

Aluna Esmerada: - Coxinhas... Nomes franceses.

Aluna Khoumba: - Franceses.

Professor François: -E você não é francesa?

Aluna Esmerada: - Não, não sou francesa.

Professor François: -Ah! Eu não sabia.

Aluna Esmerada: - Eu sou, mas não tenho orgulho de ser.

Professor François: -Eu também não. Eu também não tenho orgulho de ser francês.

Aluna Khoumba: - Por que você sempre escolhe nomes assim?

Professor François: -Khoumba, escolher nomes em função das origens de cada aluno é impossível.

Esta cena do filme, momento em que o professor solicita aos alunos que retirem do texto palavras desconhecidas, mostra um modelo de interação discursiva em que o professor não controla os turnos de fala sozinho. Apesar do evidente choque entre culturas explícito no evento discursivo, os alunos interagem com o professor e entre seus pares sobre o tópico discutido naquele momento e acrescentam novos elementos à discussão em andamento constituindo o padrão discursivo simétrico. Dessa forma, há melhor distribuição das falas sugerindo que nesta cena do filme ${ }^{3}$, especificamente, houve maior interação. A atuação do professor em permitir que o aluno explicite seu ponto de vista é, portanto, fator determinante para a aprendizagem. A permuta de papéis, ou seja, a variação em termos de papéis interacionais permite maior qualidade das participações. Entretanto, no episódio final, momento em que o professor indaga aos alunos sobre o que aprenderam durante o ano, nenhum deles relata sobre conteúdos discutidos nas aulas do professor François. Como se articula, então, a dinâmica das interações e suas relações com o ensino? Os estudos de Bakhtin e de Vygotsky apontam para uma possível resposta:

3 Outro momento de interação marcante no filme trata-se do episódio em que os alunos foram ao laboratório para concluir a atividade do autorretrato. 
Bakhtin analisou a estrutura da enunciação na língua corrente pela inter-relação entre significação, sentido e valor apreciativo. Vygotsky, da mesma forma, buscou apreender a estrutura do pensamento a partir do sentido e da intenção afetivo volitiva presentes na interação verbal. Ambos distinguem sentido e significado da palavra compreendendo sentido em seu aspecto concreto, dinâmico, contextual (FREITAS 2006 apud SOCHA e MARIN, 2009, p. 3)

No discurso interacional os participantes têm seus discursos atravessados por fluxos culturais diversos. A aprendizagem é, portanto, resultado de procedimentos sociointeracionais entre os participantes, empenhados na construção do sentido e do conhecimento. Não se pode esperar que o aluno idealize um novo sentido a tudo que lhe é apresentado ou que realize grandes conexões sem as devidas interações em sala. Concordamos com Snyders apud (SOCHA e MARIN, 2009, p. 5) quando argumenta que devemos esperar do aluno que ele não se limite a reprodução e repetição mecânica, fato este bastante evidente no filme analisado, e sim que transforme a cultura que a Escola lhe dispõe.

\section{Considerações finais}

A partir da análise do discurso pedagógico interacional presente no filme "Entre os muros da Escola" verificamos que as interações desencadeiam conflitos em sala de aula e são atravessadas por relações de poder e por choques culturais. Na ordem discursiva da sala de aula o professor detém o discurso de autoridade e os alunos, para entrarem nessa ordem discursiva, precisam se "submeter" à autoridade imposta pelo professor. Quando isso não ocorre, presenciamos os conflitos, e mecanismos de controle entram em jogo de modo a cercear o discurso pedagógico.

Em momentos em que ocorre maior interatividade, ou seja, em que de fato ocorre interação em seu sentido mais original, notamos que a aprendizagem é favorecida, pois essa resulta de procedimentos sociointeracionais entre os participantes, empenhados na construção do sentido e do conhecimento. Acreditamos que a permissão das contrapalavras e a permuta entre papéis interacionais são fatores determinantes para a construção de sentidos pelos alunos. No evento discursivo aula é importante considerarmos a experiência e 
sensibilidade do aluno identificando os elementos que evidenciem os caminhos do seu pensamento a respeito dos conceitos ou fenômenos conduzindo-o a um caminho de descobertas dando-lhe condições de atuar no evento social aula operando as estruturas de participação desse contexto interacional.

\title{
AN ANALYSIS OF INTERACTIVE RELATIONS IN DISCURSIVE PLACE CLASSROOM ACCORDING TO THE FILM AMONG THE WALLS OF SCHOOL
}

\begin{abstract}
Interactions that take place in classroom are permeated by power relations and can still be fraught with conflict. Language is the great battlefield where those conflicting relationships and power are struggled and materialized. The objective of this paper is to analyze how the interactive pedagogical discourse is configured in a classroom of basic education from scenes of the film "Among the walls of the School", directed by Laurent Cantet, addressing the theory of mechanisms of control of Foucault's discourse (2008) and pedagogical discourse, as an authoritarian discourse, according to Orlandi (1987). The intention is to verify to what extent the authoritarian discourse and the interaction, or the lack of it can interfere in construction of senses on part of students.
\end{abstract}

KEY WORDS: Construction of senses; Speech; Interaction; Power relations; Classroom.

\section{REFERÊNCIAS:}

COSTA, A. de C.; FONSECA-SILVA, M. da C. Considerações iniciais sobre o controle dos discursos: breve leitura de A ordem do discurso, de Michel Foucault. Revista Espaço Acadêmico, Maringá: Universidade Estadual de Maringá., n o 161. p. 49-56, mensal. 2014. Disponível em: http://www.periodicos.uem.br/ojs/index.php/EspacoAcademico/article/view/23889. Acesso em 10 maio 2019.

ENTRE os muros da escola. Direção: Laurent Cantet. Produção: Caroline Benjo. Roteiro: Laurent Cantet, François Bégaudeau, Robin Campillo. Intérpretes: Arthur Fogel, Cherif Bounaidja, Dalla Doucoure, François Bégaudeau e outros.França, 2008, ( 128 $\min )$.

FOUCAULT, M. A ordem do discurso. 17 ed. São Paulo: Edições Loyola. 2008.

GERALDI, J. W. et al. (org.). O texto na sala de aula. 5 ed. São Paulo: Ática, 2011.

MOITA LOPES, L. P. Variação de padrões interacionais em dois grupos de aprendizes de leitura em língua materna. Revista TB (UFRJ), Rio de Janeiro, 117: 107-120, abr./jun., 
1994. Disponível em: http://www.quadernsdigitals.net/index.php?accionMenu=secciones.VisualizaArticuloSeccionIU.visualiza\&proyecto_id=361\&articuloSeccion_id=4697. Acesso em 18 maio 2019.

ORLANDI, E. P. O discurso Pedagógico: a circularidade. In: . A Linguagem e seu funcionamento: as formas do discurso. 2 ed. Campinas: Pontes, 1987. p. 15-23.

SOCHA, R. R.; MARIN, F. A. D. G. A dinâmica das interações em sala de aula e a construção de sentidos pelos alunos. Anais do XVIII Simpósio Nacional de Ensino de Física. v. 1.Vitória-ES, 2009. Disponível em: http://www.cienciamao.usp. br/tudo/exibir.php?mi$\mathrm{dia}=$ snef\&cod=_adinamicadasinteracoesem. Acesso em 15 maio 2019.

SOUZA, E. M. F. A aula de Português como Instância de Produção e de Circulação de Conhecimentos Linguísticos e não Linguísticos. In: SOUZA, E. M. F.; CRUZ, G. F. (Orgs.). Linguagem e ensino: elementos para reflexão nas aulas de língua inglesa e língua portuguesa. Vitória da Conquista: Edições UESB, 2009.

SOUZA, L. M. T. M. O conflito de vozes na sala de aula. In: CORACINI. M. J. R. F. O jogo discursivo na aula de leitura. São Paulo: Pontes, 1995.

Recebido em: 01/06/2019. Aprovado em: 30/06/2019. 